\title{
EDUCACIÓN SUPERIOR: SITUACIÓN DEL PERSONAL ACADÉMICO Y DE GESTIÓN
}

\section{De las dotaciones}

No existe un estudio que pueda ser aplicado en general a las instituciones de que tratamos, pues su diversidad, el ámbito que abarcan, la complejidad que alcanzan, entre otros aspectos, hacen imposible adoptar un modelo específico. Sin embargo, intentaremos alcanzar un consenso respecto de cantidades y de especialidades o niveles.

Definimos una estructura ideal como aquella que, al máximo de eficiencia y calidad, es capaz de resolver los problemas y conflictos temporales que son propios de su giro; es decir, puede enfrentar los periodos normales de funcionamiento y los de mayor carga de trabajo (en lo administrativo, las matrículas y el registro curricular antes y después de los exámenes; en lo docente, preexamen y posexamen y periodos de proyectos concursables).

En un modelo relacional-funcional, esta estructura podría ser: docentes -profesores en todas sus jerarquías, 30 a 35\% del total (se incluye a instructores y ayudantes)-; personal de apoyo, 60 a $65 \%$-se incluye a directivos, profesionales, técnicos, administrativos y auxiliares-, todos ellos en plantas. Se permitiría un $5 \%$ de personal a honorarios, por periodos de prueba y por proyectos específicos de plazo determinado o fijo.

Todo lo anterior supone, además, una selección muy eficiente y profesional de personal, con determinaciones de cargos-puestos muy afinada y con una visión de los objetivos de la institución realmente asumida.

Dado que esto no ocurre, luego de una determinación de conveniencia se puede capacitar o perfeccionar al personal de acuerdo 
con las necesidades de la institución y, luego, con las del capacitado. Esta experiencia se puede mejorar con un proyecto de capacitación de precontrato, al que todos los postulantes que lo ameriten deben estar obligatoriamente sujetos (requisito de ingreso).

Nos referiremos, en términos generales, a la Universidad de Chile. En términos porcentuales, la situación de la dotación es la siguiente:

\begin{tabular}{lll}
\hline Personal académico-docente & & \\
\hline Profesores titulares & $14 \%$ & \\
Profesores asociados & $15 \%$ & \\
Profesores adjuntos & $07 \%$ & ${ }^{*}$ Equiv. a profesor asistente \\
Profesores asistentes & $34 \%$ & "Equiv. a profesor adjunto \\
Instructores & $22 \%$ & \\
Ayudantes & $08 \%$ & \\
\hline
\end{tabular}

Esto significa que los profesores son un $70 \%$ y los ayudantes e instructores un $30 \%$ de la planta docente (carrera ordinaria más carrera docente). Lo que podría redundar en que las posibilidades de que los cargos de menor jerarquía suban al estrato inmediatamente superior no se puedan concretar, dadas las características y requisitos que ello implica en cuanto a la medición de calidades.

El ideal aparente para esta planta de docentes-académicos sería:

\begin{tabular}{lll}
\hline Personal académico-docente & & \\
\hline Profesores titulares & $15 \%$ & \\
Profesores asociados & $25 \%$ & \\
Profesores adjuntos & $07 \%$ & Equiv. a profesor asistente \\
Profesores asistentes & $28 \%$ & Equiv. a profesor adjunto \\
Instructores & $22 \%$ & \\
Ayudantes & $10 \%$ & \\
\hline
\end{tabular}

* Sólo cambia el requisito de tiempo para permanecer en la jerarquía. La estructura determinada es un reflejo de la situación de los cargos de planta, contrata y suplencias, para todos los casos. 


\begin{tabular}{ll}
\hline Personal de Colaboración & \\
\hline Directivos & $04 \%$ \\
Profesionales & $17 \%$ \\
Técnicos & $27 \%$ \\
Administrativos & $30 \%$ \\
Auxiliares & $22 \%$ \\
\hline
\end{tabular}

Las sumas de ambas plantas de personal nos entregan que la planta docente alcanza a un 36\%, mientras que la de personal de apoyo a un $64 \%$. Aparentemente, se encontrarían en un equilibrio relativo; sin embargo, para ninguno de los dos casos se consideró el personal que labora bajo la modalidad de convenio de honorarios, que corresponde a un porcentaje extra, equivalente a un $18 \%$ aproximado y que fluctúa mes a mes de acuerdo con la cantidad de proyectos vigentes.

Como resultado de este ejercicio tenemos que, para una planta académica óptima, deberíamos hacer los siguientes ajustes:

\begin{tabular}{lrl}
\hline Personal académico-docente & & \\
\hline Profesores titulares & $+1 \%$ & \\
Profesores asociados & $+10 \%$ & \\
Profesores adjuntos & $=0 \%$ & Equiv. a profesor asistente \\
Profesores asistentes & $-6 \%$ & Equiv. a profesor adjunto \\
Instructores & $-7 \%$ & \\
Ayudantes & $+2 \%$ & \\
\hline
\end{tabular}

Se observa que debemos aumentar en un $1 \%$ los profesores titulares, en un $10 \%$ los profesores asociados; asistentes y adjuntos deben disminuir en un 6\%, los instructores en $7 \%$ y los ayudantes aumentar en un $2 \%$. El porcentaje anómalo es el de los profesores asociados, cuyo déficit es muy significativo y es necesario corregirlo.

De los datos observados se desprende que la planta de personal de apoyo debería bajar proporcionalmente en cada uno de los segmentos, entre el 8 y el 10\%, ocupado en parte por personal de outsourcing y honorarios. 
No se analizan los problemas de envejecimiento de ambas plantas, causados en parte por el daño previsional que impide a los funcionarios jubilar y facilitar con ello el normal avance en la carrera funcionaria y la renovación de cuadros de planta.

\section{El recurso humano calificado en la Universidad de Chile}

\section{Consideraciones generales del ámbito académico-docente}

Para ingresar a la carrera universitaria se requiere, como paso indispensable, realizar la jerarquización académica, a través de un proceso -algo complejo y supuestamente objetivo- de calificación y evaluación de antecedentes, realizado por una comisión especial. El informe de esta comisión determina la jerarquía en la que comienza la carrera del solicitante-ayudante, instructor, profesor (asistente, adjunto, asociado, titular)-, ya sea en la carrera regular u ordinaria o en la docente (dos carreras orientadas a distintas tareas y requisitos, como, asimismo, reglas de ascenso). Pasado dicho proceso, éste recién puede postular a un concurso público, con los requisitos determinados por la Ley $\mathrm{N}^{\mathrm{o}} 18.834$ y el DFL N 29 de 2005. Una vez resuelto el concurso, puede asumir sus funciones quien haya sido elegido para el cargo. Han transcurrido para ello al menos tres meses. Se trata, además, de uno de los sistemas de calificación de mayor exigencia en el medio universitario, motivo por el cual tiende a acumular académicos en la parte baja de la jerarquía, impidiendo avanzar en la carrera docente por los múltiples requisitos de calidad.

Con este procedimiento se pretende medir la calificación del docente, pero no puede medir la calidad del mismo. Un doctor puede no ser capaz de entregar en el aula los conocimientos para los cuales está calificado y sí lo puede hacer un titulado sin grado académico. Por ello, es necesario realizar una planificación de capacitación orientada a desarrollar nuevas competencias en los funcionarios de ambas plantas. Esto acarrea 
otra dificultad: no existe aún un plan que permita incentivar el retiro para permitir el ingreso de académicos jóvenes o impulsar un tiraje normal de las plantas docentes renovando su personal; por otra parte, fomenta el envejecimiento del cuerpo docente. Todo ello redunda en la inexistencia de una "carrera funcionaria docente normal".

Respecto de la calificación del personal, ésta quedaría cautelada, en el caso del personal académico-docente, por el sistema de jerarquización; sin embargo, ello no garantiza la calidad en cuanto a entrega de conocimientos en aula. Por eso es necesario invertir en sistemas de perfeccionamiento y capacitación que permitan alcanzar grados mayores de calidad. Para ello, la Universidad de Chile está invirtiendo ingentes recursos en el perfeccionamiento de todo su personal, situación que se detalla en la tabla siguiente:

Inversión en capacitación desde 1999-2000 a abril de 2006.

\begin{tabular}{lccc}
\hline Estadísticas generales & $\mathrm{N}^{\circ}$ de hrs. & $\mathrm{N}^{\circ}$ de part. & \multicolumn{1}{c}{ Valor \$ } \\
\hline $1999-2000$ & 66.600 & 2.889 & 223.973 .854 \\
2001 & 155.364 & 7.355 & 654.757 .721 \\
2002 & 155.985 & 5.534 & 624.232 .122 \\
2003 & 127.224 & 4.105 & 486.129 .952 \\
2004 & 113.454 & 3.675 & 408.189 .488 \\
2005 & 17.399 & 2.233 & 327.731 .639 \\
abril 2006 & 19.780 & 1.118 & 149.352 .717 \\
Total & 655.806 & 26.909 & 2.874 .367 .493 \\
\hline Gastos de administración 1999 a 2005 & & & 492.196 .351 \\
\hline Total de inversión & & & \\
(capacitación + gastos de administración) & & & 3.366 .563 .844 \\
\hline Promedios anuales & 93.687 & 3.844 & 480.937 .692 \\
\hline
\end{tabular}

Los promedios alcanzados en personal corresponderían a 3.894 capacitados anuales, tanto en docencia, gestión y cursos generales y específicos para el desarrollo de actividades complejas, con un promedio anual de 93.687 horas de capacitación. 


\section{De la seguridad del empleador a la seguridad del trabajador}

Antes de 1973, aproximadamente, existía la creencia de que el solo hecho de trabajar en cualquier universidad traía prestigio $y$, por ende, era una externalidad positiva para el trabajador, especialmente el docente. Sin embargo, en la actualidad es este mismo docente el que exige una remuneración más alta y agrega a eso la propiedad del cargo, la que una vez obtenida pasa a ser como una especie de seguro de vida laboral para el interesado.

Para evitar esta situación se emplea el recurso de los nombramientos a contrata, los que deben ser renovados cada año (siempre que el jefe directo del funcionario así lo decida). Ello cautela que las personas deban realizar una serie de tareas, a saber: docencia, investigación, extensión, creación y publicaciones, de acuerdo con el número de horas por las cuales tiene relación con la universidad. De no cumplir, queda automáticamente evaluado en una lista inferior a la de excelencia y debe aumentar su esfuerzo para que esta renovación se le otorgue nuevamente. Ello se ha transformado en una práctica frecuente que hay que corregir.

La pugna de las instituciones privadas por captar a los docentes con mejor evaluación en aula ha permitido que se desarrolle esta competencia que, se pretende, es regulada por el mercado de la docencia. Sin embargo, en la realidad resulta que las instituciones de mayor prestigio, que invierten en capacitar mejor a su personal, no pueden retenerlo por la imposibilidad de pagar remuneraciones mejores, y es inevitablemente atraído por los sectores de mayor disponibilidad y agilidad financiera.

En algunos casos es posible mantener al personal altamente calificado enfatizando en su seguridad laboral: la calidad de cargo en propiedad a la que pudiere quedar sujeto principalmente el académico. Pero también hay dificultades: supongamos que existe un docente con ocho años en la jerarquía de profesor asistente. Desde el punto de vista de los plazos debería rejerarquizarse y si 
no cumple con los requisitos para pasar a la jerarquía de asociado, según el reglamento, debería abandonar su empleo. Pero, ¿como hacerlo si posee cargo en propiedad? ¿Qué normas serían aplicables entonces para estos eventos? ¿Correspondería suprimir el cargo? Estos y otros problemas son las que hoy deberemos comenzar a solucionar.

Recibido: 24 de mayo de 2006 Aceptado: 8 de junio de 2006 